\title{
DISCERNING BEHAVIOURAL DESIGN: A CONCEPTUAL MODEL
}

\author{
P. R. Khadilkar ${ }^{\otimes}$ and P. Cash \\ DTU-Technical University of Denmark, Denmark \\ $\triangle$ prakha@dtu.dk
}

\begin{abstract}
Behavioural design has emerged as an important domain of design practice and research due to its ability to deliver the desired outcomes beyond technical designs. Research on behavioural design is not successful in discerning it from other design domains, which is important for theory building. This paper discerns the unique characters of behavioural design by tracing the emergence of behaviour in design. Twelve interviews from six behaviour design cases belonging to four firms has been used to further discern the unique characteristics resulting into the conceptual model of behavioural design
\end{abstract}

Keywords: behavioural design, design for behaviour change, design theory, human behaviour, human-centred design

\section{Introduction}

Behavioural design has emerged as a new and important domain of design practice and research (Cash et al., 2017). In this age of technological advancements and complex interconnected world, technical capabilities of the products alone is not sufficient. The emphasis is on the experiences achieved through design of the systems. Designers have mastered the ways to alter the physical laws and effects to achieve the desired outcomes. After achieving mastery on non-autonomous entities, the emphasis now is to maximize the benefit through improving the efficiency of humans - the autonomous entities. This is done by working with them to understand and change the underlying psychological processes. Behavioural design is thus a key tool to achieve the efficiency and the experience through better behaviours. There is lot of evidence to support the use of Behavioural design in practice. For example, a European Technical Report highlighted that increases in sustainable energy use of up to $20 \%$ are yet to be realised through behaviour change despite years of technological advances. Behavioural design has resulted into long-term improvements in, for example, electricity consumption (up to $13 \%$ ), waste (up to $32 \%$ ), water use (up to $7 \%$ ) (Abrahamse et al., 2005). In a Meta-analysis, users receiving behaviour change interventions report significantly better on physical activity than those in control conditions (effect size (d) 0.21) (Taylor et al., 2012). By evoking, nudging, persuading, or motivating people to behave in desired ways behavioural design deliver new ways of bringing positive change (Tromp et al., 2011). Behavioural design is not only effective, sustainable, and ethical, since it aligns user and societal interests (Tromp et al., 2011), but also prevents rebound effect, which reduces the efficiency gains by as much as $50 \%$ (Greening et al., 2000). Thus, behavioural design offers great potential in comparison to more traditional innovation approaches in addressing key healthcare challenges. 
This new domain uses the knowledge from many disciplines like psychology, cognitive science, economics and social sciences etc. that are relatively distant from traditional design knowledge. The application of this new field is also not distinct, as it could support the sustainable design, healthcare design, social design, design for development etc. Thus, it is not a domain linked with any specific application, limited to any specific industry, or to any specific normative foundation like sustainability.

Literature on behavioural design is slowly increasing, yet it currently lacks a definition accepted by the design fraternity. This paper has its origins in the fuzziness that exists in the behavioural design literature. The literature highlights that design is not neutral and affects the human behaviour, and on the other hand it also elaborates the 'active' (Tromp et al., 2011) or 'overt' role of design in changing behaviours (Niedderer et al., 2018). The two arguments present conceptual confusion about the boundary where the traditional design becomes behavioural design. Critically, this lack of conceptual clarity in definition has hindered efforts to discern the unique challenges and opportunities of this domain from traditional design or develop theory in this area (Cash, 2018). Identifying uniqueness is important to understand its effects on design process, design thinking, and project planning. The aim of this paper is to discern the uniqueness of behavioural design. For this, along with design literature this paper uses a number of case studies in leading behavioural design consultancies in Denmark. The semi-structured interviews cover process, design thinking, and project planning related aspects of behavioural design. The thematic analysis of the interviews resulted in the identification of several unique characteristics of behavioural design. As such, this work provides the basis for further theory development in behavioural design.

Section 1 categorizes the instances of behaviour in design. The idea is to define behaviour in design and identify the various instances of behaviour that are important for design. The second section reviews the evolution of behaviour in design, to understand the position of behaviour in traditional design. Third section discerns the domain using the thematic analysis of behavioural design case studies from Danish design consultancies. Fourth section presents the model of behavioural design that highlights the uniqueness of this domain. The paper ends with discussions and conclusions about how this understanding support the advancement of this domain.

\section{Categorizing behaviours in design}

Understanding the role of behaviour requires defining the behaviour and understanding how various dimensions of behaviour affect design. This is a prerequisite to discuss behaviour in design literature. First step in this regard is defining behaviour. Behaviour is defined as 'the way in which one acts or conducts oneself, especially towards others' ("Behaviour", n.d.). Operationally, Fishbein and Ajzen (2010) define the behaviour using four components, "the action performed, the target at which the action is directed, the context in which it is performed, and the time at which it is performed. A simple example is buying (action element) a General Electric (GE) dishwasher (target) at a Sears Department Store (context) in the past 30 days (time)". Both the definitions highlight that the most defining aspect of a behaviour is an action. The lifecycle phases of product need distinct actions for the fulfilment of desired functions. The actions could be categorized as, 1) actions related to buying and acceptance of a technology, e.g., buying energy efficient televisions (Young et al., 2010) 2) actions related to usage and maintenance of a technology, e.g., usage of heating system (Lilley et al., 2017), and 3) actions related to end of life of technology, e.g., recycling of products after use (Darby and Obara, 2005). Contexts affect the action by putting the users in different mind-sets. The context can have three categories. 1) Behaviours in an industrial context, e.g. worker's behaviour related to safety. Autonomy of the professional employee is generally within the bounds of legal codes and corporate codes of conduct, and best practices (Poel and Royakkers, 2011). At the same time the environments in the industrial setup is predictable and controllable. 2) Behaviours in social context, e.g. the way in which commuter behaves in a railway station. 3) Behaviours in personal context, e.g. the consumption of water while using shower. Tromp et al. (2011) distinguish the public and private context and elaborate how it affects behaviour. The lifecycle consideration in actions covers the temporal dimension associated to a product or technology. The time in the product lifecycle demands 
decisions and actions that require different commitment and involve different resources. Authors will use this constrained categorization, as it is sufficient to discuss the role of behaviour in design.

\section{Tracing the emergence of behaviour in design}

The aim of this section is to trace the historical consideration given to human behaviour in design. This section studies the implicit as well as explicit inclusion of human behaviour in the various generic as well as domain specific models of design. The idea is to look into how human behaviour is included in the design model and methodologies.

\subsection{Generic models of design}

Generically design models are aggregated into two categories (Cross, 2000), descriptive and prescriptive. Roozenburg and Eekels (1995) categorize them as the basic design cycle and the phase models of design. These models discuss the generic nature and process of design without referring to any specific use context or application. However, at this generic level, Cross (2000) do not discuss the role and effect of human behaviour on the product. On the other hand, Roozenburg specifically discuss the aspects related to human behaviour in explaining the basic design cycle. While elaborating analysis in design, Roozenburg and Eekels elaborates that (1995, p. 90), desired functions of the new product are the intended behaviours, not only technical "but also the psychological, social, economic and cultural" which should be fulfilled by the product. During the synthesis phase Roozenburg and Eekels suggest the use of behavioural theories and methods to perfect the concept and to addressing the uncertainties associated with the concept (Roozenburg and Eekels, 1995, p. 179). This essentially suggests that aspects related to human behaviour is the critical basis of the concept generation. Roozenburg and Eekels also specifically refer to behaviour in elaborating simulation (1995, p. 91), where the possible behaviour and properties of new product are tested using models that use knowledge from technological as well as behavioural domains. Also, while discussing a product as system in elaborating the phase model, Roozenburg and Eekels mention that (1995, p. 96), "Products are systems and can themselves be part of more comprehensive man-machine systems...... Each system has an environment, which consist of the entirety of elements outside the system, which influence its behaviour". Roozenburg and Eekels is exceptionally clear and elaborate in discussing the role of human behaviour in design at descriptive level, however at prescriptive level, i.e., while suggesting methods for designing, authors do not prescribe methods that could include the behavioural. This could be due to the general state of design research at the time of publication of those books. Another relatively older book specifically model in the humans and behaviour in design of technical systems. This is the prominent and explicit representation of behaviour in the design.

The early influential book, 'Theory of technical systems' (Hubka and Eder, 2012) highlight the generic role that humans play in the technical systems from three aspects (as highlighted in the Figure 1). First aspect drives the purpose of designing technical system (Hubka and Eder, 2012, pp. 19-22). The book refers to goals of satisfying the human needs, the perceived deficiencies in the world around, as the motive behind the design of technical systems. There is brief but elaborate discussion about the Maslow's hierarchy of human needs, market pull and technology push. Secondly, humans are discussed as the 'operand', defined as, "the material, energy and information that goes through the process" (Hubka and Eder, 2012, p. 22 and 26). The humans are considered as the object that could be transformed through the technical system. The third aspect is humans as the operators who exert effect on the operand. The first aspect that links the technology to fulfil the human needs is originated from the broader definition of 'Technology' in German, that considers the artefacts embedded in the society and its influence on each other (Hubka and Eder, 2012; Mitcham and Schatzberg, 2009). Hubka and Eder, elaborate that this conception of the technical systems is dependent on the causality of effects, and specifically highlights that humans and social relations are the least predictable due to the 'free choice' of humans. However, after this initial critical emphasis on humans the remainder of theorization of technical systems does not focus on humans and their behaviour. 


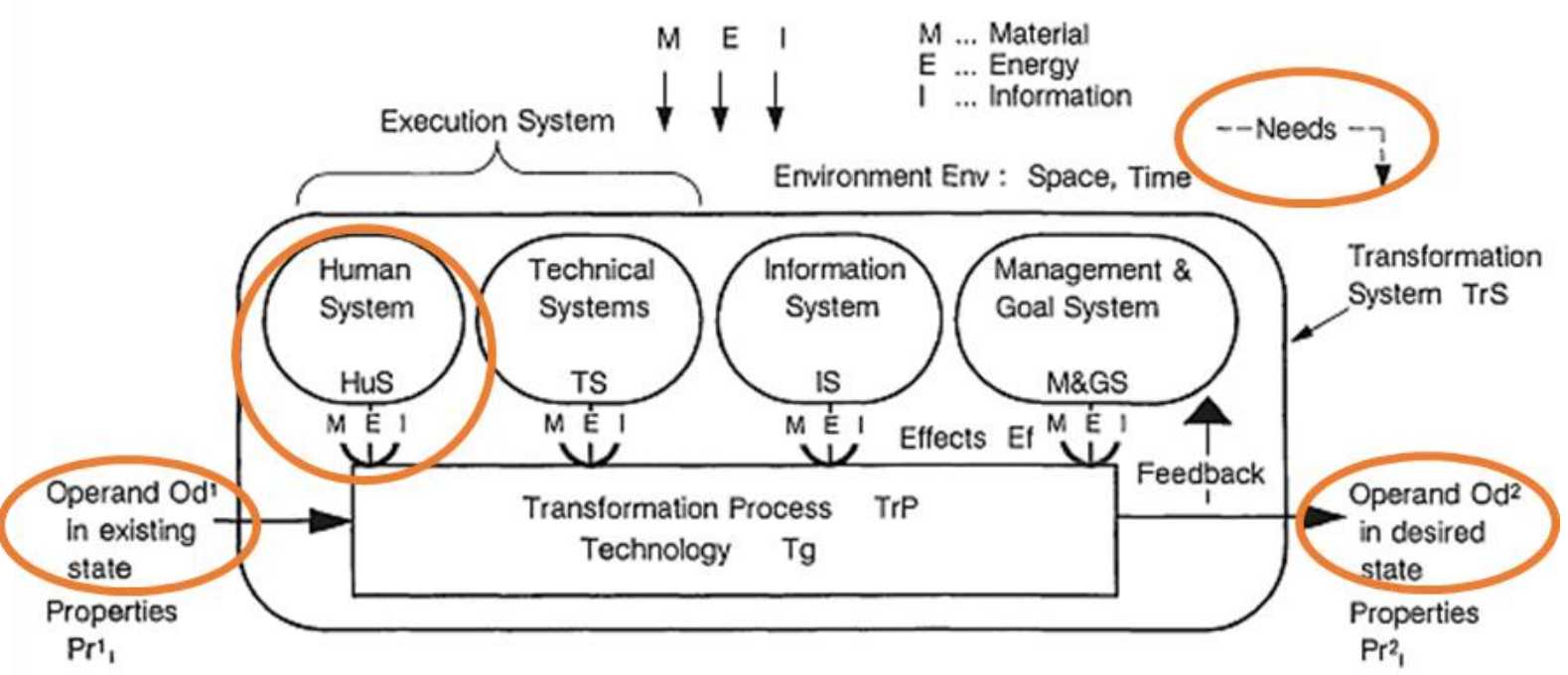

Figure 1. Modified model of the transformation system - elements and examples source (Hubka and Eder, 2012, Page 24)

Another known model that claims to be both descriptive and prescriptive is the Function-behaviourStructure model. The behaviour in this model is not the human behaviour that we intend to look into this paper. The behaviour is the technical functions that the intended product achieves due to its structural qualities. The inability in differentiating between the structural and intentional functions is an important critique of the conceptualization of function and behaviour (Dorst and Vermaas, 2005). However, design literature discusses the intentionality of human in discussing the function of technical artefact yet does not find a good way to operationalize it by transforming into technical behaviours. Another approach is to find out how the behaviour is captured in design methods, as they are structured procedures to operationalize the models. The search for methods in four books (Cross, 2000; Otto and Wood, 2001; Roozenburg and Eekels, 1995; Ulrich and Eppinger, 2000) show that there are no specific methods that explicitly focus on integrating the behavioural aspects in design. In conclusion, the overview of the design models show that few resources elaborate the role of human behaviour in design, however the support to operationalize it is missing.

\subsection{Application focused design approaches}

This section will review the design approaches that have clearly defined focus and scope. During the industrial revolution, engineering design was of prime importance and the approach was that the 'humans had to train and change themselves to fit the machine'. This changed due to the practical needs, technological advancements and linguistic developments after world war II (Wickens, 1992). The advancements made the technologies powerful and faster, which multiplied the negative outcome of an error. The complexity of actions required to operate these machines surpassed the resources available to perform the action. The accidents during the World War II convinced the researchers about the need for understanding the limits of physical and cognitive human abilities, and the need for designing the interfaces between technology and humans within these limits. At the same time, better understanding of the mental abilities provided the basis to fit the technologies well within the human capabilities. The Human factors and ergonomics domain has developed detailed processes and methods to ensure that the actions that a technology demands from humans are within the physical and mental limits. The Human factors specialization considers humans as an important resource that plays crucial role in fulfilling the technical function. This view also sometimes takes the approach like 'humans in loop' where much discussion is about how to replace human beings in critical applications, like safety (Cranor, 2008). However, the design thinkers started realizing that humans are autonomous and are the most critical entity to fulfil the technical function. This slowly resulted into the new approach to design that was, 'Human Centred'. 
After Industrial era, with increased purchasing capacity of individuals, more and more products were for the personal consumption. The individuals had resources to own industrial products and thus they could exert their autonomy in decisions related to buying the products and the affective aspects of design became crucial. The humans were not only the resources but also the direct buyers and consumers of the technology, a much powerful position than earlier (van der Bijl-Brouwer and Dorst, 2017; Norman, 2013). The fulfilment of technical functions was not sufficient for products to succeed. The non-technical functions related to affective outcomes became crucial. Understanding the humans required the understanding of the basis of their actions. The new approaches for this purpose, like Human centred design (Giacomin, 2014), Participatory design (Bjögvinsson et al., 2012) and co-creation (Sanders and Stappers, 2008), demanded the designer to leave the expert position and become a facilitator or an assimilator of the relevant knowledge (Sanders and Stappers, 2008). These new mind-sets and approaches required development of new methods like contextual inquiry, personas, generative design tools etc. That intends to base the design into how people behave and why (van der Bijl-Brouwer and Dorst, 2017; Kumar, 2012). The understanding and prediction of affective non-technical responses required understanding of the psychology of human behaviour. However, observations alone were not able to explain, 'why people behave the way they do?' The research in human psychology (Tversky and Kahneman, 1974) presented interesting observations on seemingly irrational behaviours of people in accessible manner to non-psychologists like designers. The work of researchers in cognitive psychology made it mainstream in design and tried to explain, 'why attractive things work better' (Norman, 2004, 2013). This resulted into major change in design approach and process. Experience design (Hassenzahl, 2013), semantic design (Krippendorff, 1989, 2004, 2005) and emotional design (Desmet and Hekkert, 2007; Norman, 2004) tried to understand and predict the outcomes of interaction of the products. This intended to understand, how humans may behave in a specific situation pertinent to a given technology and why, and what it means to them. The inherent logic was that the meanings would drive the human actions, whether they are helpful or deterrent for the achievement of the envisaged function. This would directly affect the acceptance of the technology by its buyers. However, in these approaches, design treats the human psychology as sacrosanct, and does not modify it directly.

The most overt consideration to humans and their actions is evident in behavioural design and behavioural design type of design domains. Here, designers do not use the affective mind states as goals to achieve through design, but uses the human mind and actions to bring in the change (Niedderer et al., 2018). Researchers also realized that the efficiency and experience of the outcomes of any social system could be improved through improving how humans behave (Tromp et al., 2011). The research in human psychology was able to elaborate the reasons behind the irrational behaviours (Tversky and Kahneman, 1974) on which most of the positivist models of economics (Thaler, 2015) and design were built. The behavioural design uses the science of human behaviour to change the impact of the developmental programs, health care etc. (Bandura, 1998; Datta and Mullainathan, 2014; Michie et al., 2015). Thus, the role and importance of humans in design approaches changed from it being an 'operator' to an important stakeholder whose psychological states affect the success of a technology.

\section{Discerning the characteristics of behavioural design through case studies}

Earlier section elaborate that behavioural design lacks theory to define the domain. This paper thus uses the theory development approach using case studies (Yin, 2014) to develop and refine the understanding of the unique features and challenges of behavioural design.

\subsection{Methodology}

Researchers identified Design consultancies providing the behavioural design services in Denmark using personal contacts and through internet search. Researcher presented the overall aim of the research as, 'understanding the process, practices and challenges in executing behavioural design projects' and requested the consultancies to provide the list of projects that they would consider as behavioural design projects along with a small brief. The researchers selected the case studies, and interviewed the main 
decision makers, like project manager, lead designer, or behaviour analyst using the structured interview guide. The thematic analysis in this paper uses six case studies from four design consultancies, involving twelve interviews. The thematic analysis uses the detailed account of the definition of problems and solutions in the behavioural design, and the challenges linked with practicing behavioural design. The theoretical understanding guides this specific focus of looking at the data and thus the part of the data that deals with these aspects has been read and coded. The thematic analysis intends to identify the broader recurring patterns at 'semantic or analytical level' and do not deal with the 'underlying ideas, assumptions and conceptualizations- the ideologies' (Braun and Clarke, 2006). The codes resulted into multiple themes. The consistent themes emerged after two iterations.

\subsection{Thematic analysis}

The analysis resulted into two broad themes, one related to characteristics of the projects and another related to the challenges faced by the practitioners while executing behavioural design projects.

\subsubsection{Theme 1 - Characteristics of behavioural design projects}

Goals of behavioural design projects are the problematic behaviours and/or target behaviours Team defines the goal of the design projects in terms of the problematic behaviours and/or target behaviours and not in terms of an artefact. Project Manager and Lead designer (Case 4) said, "we set out to find out from the beginning what are the target behaviours". Lead designer (Case 1) mentioned, "I think there is lot of behavioural aspect to it ... in terms of not reading and trying to solve whatever problem you meet ". In some of the projects that were not pitched as behavioural design projects at start, once the importance of the behavioural aspects were realized, the project goals were defined in terms of either avoiding the problematic behaviour or achieving target behaviour or both. This is evident in Lead behavioural designer's (case 6) comment, "To begin with, the target was very clear, right? we needed them to use this system instead of the other system". The purpose of artefacts or interventions in these projects was to fulfil the behaviours.

Not all solutions modify human psychology - Not all behavioural problems had the solutions that changed the psychological causes of the behaviour. The solutions also affected the behaviour by removing the causes for the problematic behaviour or by simplifying the task or the environment. Lead designer (Case 1) here emphasizes that the system steers the right behaviour, "So beforehand in order to do it right you have to understand, and now you just have to do it the right way in terms of what the systems tells you to do". On other hand, lead designer (Case 4) use psychological aspects linked to psychological constructs like mental models, "we constructed a campaign that was like a national campaign that utilized a mental model of burglary". Another example is about converting a desired behaviour from a conscious process to an unconscious habitual process. The project manager and lead designer (case 5) elaborates the idea, "something you haven't done before, and [if] you have to do it now every day, what's the best way to do it? Try to attach it to an existing habit".

Projects are complex and constrained - The team members perceived the behavioural design projects as complex and highly constrained. The project manager and lead designer (case 5) said, "right now, where we can't just relocate people into new homes, how much can behaviour design actually move the needle and improving through be targeting behaviours?" The Project Manager and Lead designer (Case 4) felt that the complexity also arise out of the complex nature of problems, "that is the main problem actually, that it's very broad and it's very complex and it's very abstract for most people". The constraints also originate in social and cultural contexts in which the projects are situated. Behavioural designer (case 6) commented, "they made so much resistance, so our new task was actually not going from [physical document] to [Information technology based system] but, having the new system adopted by [the users]"

\subsubsection{Theme 2 - Challenges in behavioural design projects}

Behaviour as the last resort - Most designers iterated that the behavioural design was the last resort after the failure of all the technical fixes. The Project Manager and Lead designer (Case 4) mentions, " the main problem is that we think it's a technical problem... behavioural science shows us that... people.... have some general tendencies that we need to take as a point of departure in order to 
construct design or communication that makes sense to people". Behavioural designer (case 6) frustratingly mentions that, "I would definitely say that $90 \%$ of all projects with behavioural design that I have been in, or 95\%, are working with a solution already developed"

Inability to understand the data intensive nature of behavioural design - Behavioural designer has to understand the real problematic behaviours and the psychological factors that are driving it. This, according to designers, requires higher resources. However, often clients and colleagues not experienced in design do not understand these demands. This is reflected in Communication designer's (case 6) comment, "we often get challenged on the interviews, so why you need to interview, we know what is going on, or we already did the interview". Interestingly project manager (case 1) reiterate this aspect, "we have been convinced, or persuaded that, that's not necessary, we actually understand fine what our customers are saying". Lead designer (Case 1) mentions that there is appreciation about value of behavioural design, but the awareness about resource intensiveness is low, "people are quite interested in what's this with the behavioural design... but it becomes as an issue .... because you use quite a lot of time gathering the data and the data analysis... my colleagues would [question], why are you going to use that much of the budget only on the analysis of the problem"

Market placement of the companies hinder the expectations - Behavioural design being relatively new expertise that some of the established non-behavioural design companies offer, the customers have some set expectations about what to expect in the projects those have behavioural component into it. The following comment by project manager (case 3 ) highlights companies face challenges in convincing the customers in doing additional steps, " in their minds they have a great idea they come to us they just want us to build it so they can sell it. ... we try to sneak it in from the back door, all the analysis and the investigations". In some cases, the behavioural designer cannot affect the outcome much if the project formulation is in non-behavioural mode, i.e., if the agreed deliverable is an artefact rather than the desired behaviour change. The behavioural designer (case 3) iterate that this affect the outcome, "I think in this project the thing is that it wasn't really up for question whether the [product] was a good idea or not.". Lead designer (Case 1) finds it difficult to change the project after a problematic behaviour is observed later in the project, "it's always a problem to kind of tweak something that has been sold to a customer, and we want to do something else". These themes show that the behavioural design projects are different from product focussed design projects. This will result into the formulation of the conceptual model of behavioural design.

\section{Formulating a conceptual model of behavioural design}

The theoretical understanding of the emergence of behavioural design and the thematic analysis helps in discerning the behavioural design from other design variants.

\subsection{Discerning behavioural design}

All the variants of design other than behavioural design (Refer Table 1) has a goal of coming up with an artefact. These variants also affect the human action indirectly through the artefacts. Even in design variants like emotional design or experience design that evidently discuss about the psychological processes, they are used to help in ensuring that the products appeal to the customers so that they buy (action) or use effortlessly, safely or joyfully (action). In all these variants, design does not alter the psychological processes directly, but indirectly.

The thematic analysis shows that the goals of the behavioural design projects is formulated in terms of behaviours and the actual interventions or artefacts that come out are the instruments in fulfilling the behavioural outcome. This is uniquely different from all other non-behavioural design variants where the project is conceptualized in terms of an artefact. Second unique difference in behavioural design is, the involved humans are changed by purposefully affecting the psychological basis that drives the actions. This essentially needs observing the people, understanding their emotional states, building their mental models using cognitive linguistics etc. This requires the processes of human centred design, which ensures that humans undergoing change approve these changes. This is a crucial ethical consideration in behavioural design, which requires careful adherence. The Table 1 thus distinguishes the behavioural design from other crucial design variants. 
Table 1. Discerning behavioural design from other key design variants

\begin{tabular}{|c|c|c|c|c|}
\hline $\begin{array}{l}\text { Design } \\
\text { Category }\end{array}$ & Ethos & $\begin{array}{l}\text { Effect on } \\
\text { human action }\end{array}$ & $\begin{array}{l}\text { Effect on design phases } \\
\text { (examples) }\end{array}$ & $\begin{array}{l}\text { Use of behavioural } \\
\text { science }\end{array}$ \\
\hline $\begin{array}{l}\text { Early } \\
\text { technical } \\
\text { design }\end{array}$ & $\begin{array}{l}\text { Fitting humans to } \\
\text { task }\end{array}$ & $\begin{array}{l}\text { Changed } \\
\text { indirectly as a } \\
\text { consequence }\end{array}$ & None & No \\
\hline $\begin{array}{l}\text { Human } \\
\text { factors }\end{array}$ & $\begin{array}{l}\text { Fitting task to } \\
\text { humans }\end{array}$ & $\begin{array}{l}\text { Changed } \\
\text { indirectly as a } \\
\text { consequence }\end{array}$ & $\begin{array}{l}\text { Designing interfaces during } \\
\text { detailed design phase } \\
\text { (ergonomics), simulation and } \\
\text { evaluation (usability testing) }\end{array}$ & $\begin{array}{l}\text { Yes (structured and } \\
\text { direct - cognitive } \\
\text { abilities of humans) }\end{array}$ \\
\hline $\begin{array}{l}\text { Human } \\
\text { centred } \\
\text { design }\end{array}$ & $\begin{array}{l}\text { Understanding } \\
\text { humans through } \\
\text { observation and } \\
\text { co-designing } \\
\text { with them }\end{array}$ & $\begin{array}{l}\text { Changed } \\
\text { indirectly as a } \\
\text { consequence }\end{array}$ & $\begin{array}{l}\text { Needs analysis (contextual } \\
\text { inquiry), conceptualization (co- } \\
\text { design), Simulation and evaluation } \\
\text { (usability testing) }\end{array}$ & $\begin{array}{l}\text { Yes (less structured } \\
\text { and indirect - } \\
\text { behavioural } \\
\text { observations without } \\
\text { linking to theory) }\end{array}$ \\
\hline $\begin{array}{l}\text { Emotional } \\
\text { design/ } \\
\text { Experience } \\
\text { design }\end{array}$ & $\begin{array}{l}\text { Understanding } \\
\text { humans by } \\
\text { understanding } \\
\text { their } \\
\text { psychological } \\
\text { processes }\end{array}$ & $\begin{array}{l}\text { Changed } \\
\text { indirectly as a } \\
\text { consequence }\end{array}$ & $\begin{array}{l}\text { Needs analysis (Cultural probes, } \\
\text { Kansai engineering), } \\
\text { conceptualization (visceral, } \\
\text { behavioural and emotional } \\
\text { aspects), Simulation and evaluation } \\
\text { (measuring emotions, usability } \\
\text { testing) }\end{array}$ & $\begin{array}{l}\text { Yes (structured and } \\
\text { direct - measuring } \\
\text { emotions) }\end{array}$ \\
\hline $\begin{array}{l}\text { Behavioural } \\
\text { design/ } \\
\text { design for } \\
\text { behaviour } \\
\text { change }\end{array}$ & $\begin{array}{l}\text { Ethical use of the } \\
\text { human } \\
\text { psychology to } \\
\text { actively change } \\
\text { human behaviour }\end{array}$ & $\begin{array}{l}\text { Changed } \\
\text { directly and } \\
\text { purposefully }\end{array}$ & $\begin{array}{l}\text { Needs analysis ( mental models, } \\
\text { biases, measuring motivation and } \\
\text { cognition), Conceptualization } \\
\text { (Behaviour change techniques, } \\
\text { Design with intent), Simulation } \\
\text { and evaluation (no standard } \\
\text { techniques) }\end{array}$ & $\begin{array}{l}\text { Yes (Structured and } \\
\text { direct - Theory of } \\
\text { Planned behaviour, } \\
\text { Psychological } \\
\text { theories, theory of goal } \\
\text { systems, theory of } \\
\text { dual system) }\end{array}$ \\
\hline
\end{tabular}

\subsection{Formulating the conceptual model of behavioural design}

The model in Figure 2 captures the two main distinguishing characteristics of behavioural design. The definition of the problems is in terms of behaviours and technical functions hold a subservient role. The human psychology is a key resource, the technical and the material resources are in the supportive roles. The outcomes are defined in terms of target behaviours and the evaluation is based on the successful fulfilment of those goals. Behavioural design results into a system of multiple artefacts due to the need for changing the various aspects of human psychology. The artefact's critical function in behavioural design is to support the psychological change. The resultant artefacts are technical products, communications, and processes.

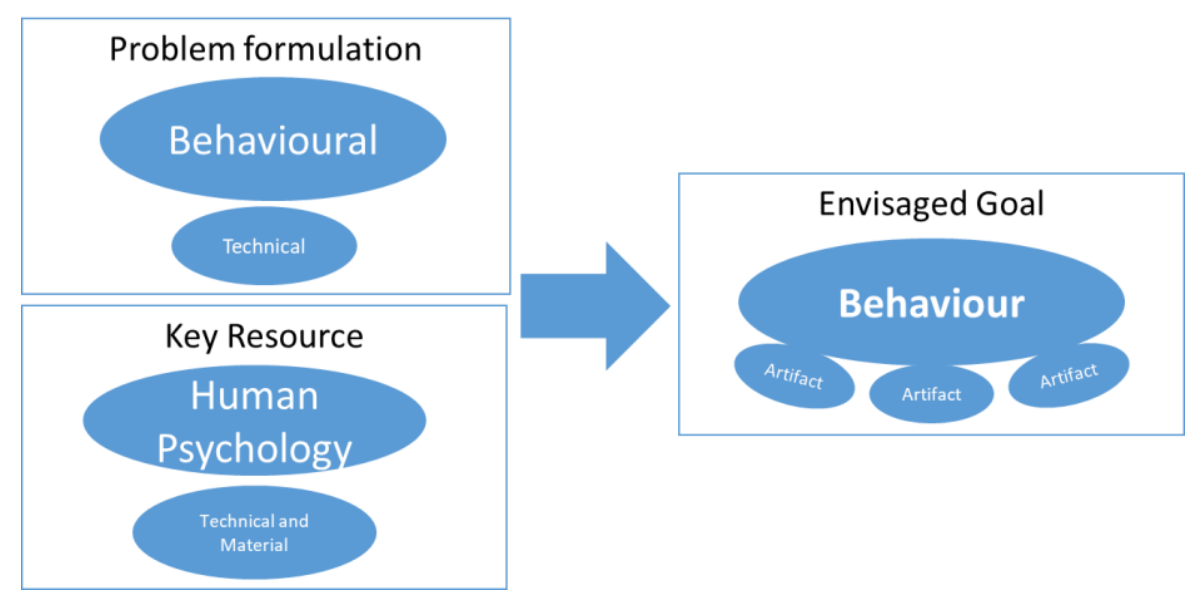

Figure 2. Conceptual model of behaviour design 


\section{Discussion and conclusion}

This paper has discerned the uniqueness of behavioural design using the literature and then by supporting it by qualitative analysis of behavioural design cases from industry. The analysis of the literature on the key variants of design showed how the role of behaviour emerged in design. This helped in understanding the scope of existing design variants in terms of the behaviour and the role it plays in the design process. The six case studies revealed the formulation of the behavioural design projects in terms of problems and solutions, and the challenges the behavioural design practitioners face. The crucial contribution of this paper is the identification of the unique characteristics of the behavioural design. It showed that, in contrary to non-behavioural design, these projects are formulated in terms of behaviours and not in terms of the artefacts. The artefacts are not the goals of the project, but they aim to fulfil the target behaviour. Another unique aspect of behavioural design is, the projects understand and then purposefully modify the psychological aspects that either are causes for problematic behaviour or provide ways to achieve the target behaviour.

This paper successfully theorizes the unique characteristics of behavioural design through industrial case studies. The discernible characters can now differentiate the behavioural design projects, which then could guide project formulation and planning based on the complexities involved in the behavioural design. The ability to distinguish the behavioural design projects presents the opportunities to study them for the challenges related to the process, design cognition, and design planning aspects. This could result into specialized design processes, frameworks, and methods for the behavioural design.

\section{Acknowledgment}

This project has received funding from the European Union's Horizon 2020 research and innovation programme under the Marie Skłodowska-Curie grant agreement No 754462. Authors also thank the twelve participants from four design firms who appeared for the interviews.

\section{References}

Abrahamse, W. et al. (2005), "A review of intervention studies aimed at household energy conservation", Journal of Environmental Psychology, Elsevier, Vol. 25 No. 3, pp. 273-291.

Bandura, A. (1998), "Health promotion from the perspective of social cognitive theory", Psychology and Health, Taylor \& Francis, Vol. 13 No. 4, pp. 623-649.

“Behaviour”. (n.d.), available at: https://www.lexico.com/en/definition/behaviour (accessed 15 November 2019).

van der Bijl-Brouwer, M. and Dorst, K. (2017), "Advancing the strategic impact of human-centred design", Design Studies, Elsevier, Vol. 53, pp. 1-23.

Bjögvinsson, E., Ehn, P. and Hillgren, P.-A. (2012), "Design things and design thinking: Contemporary participatory design challenges", Design Issues, MIT Press, Vol. 28 No. 3, pp. 101-116.

Braun, V. and Clarke, V. (2006), "Using thematic analysis in psychology", Qualitative Research in Psychology, Taylor \& Francis, Vol. 3 No. 2, pp. 77-101.

Cash, P.J. (2018), “Developing theory-driven design research”, Design Studies, Elsevier, Vol. 56, pp. 84-119.

Cash, P.J., Hartlev, C.G. and Durazo, C.B. (2017), "Behavioural design: A process for integrating behaviour change and design", Design Studies, Elsevier, Vol. 48, pp. 96-128.

Cranor, L.F. (2008), A framework for reasoning about the human in the loop, figshare.

Cross, N. (2000), Engineering Design Methods: Strategies for Product Design, John Wiley \& Sons Ltd, West Sussex, England, available at: http://oro.open.ac.uk/39439/ (accessed 15 October 2014).

Darby, L. and Obara, L. (2005), "Household recycling behaviour and attitudes towards the disposal of small electrical and electronic equipment”, Resources, Conservation and Recycling, Elsevier, Vol. 44 No. 1, pp. 17-35.

Datta, S. and Mullainathan, S. (2014), "Behavioral design: a new approach to development policy", Review of Income and Wealth, Wiley Online Library, Vol. 60 No. 1, pp. 7-35.

Desmet, P. and Hekkert, P. (2007), "Framework of product experience", International Journal of Design, Vol. 1 No. 1, pp. 57-66.

Dorst, K. and Vermaas, P.E. (2005), “John Gero’s Function-Behaviour-Structure model of designing: a critical analysis", Research in Engineering Design, Springer, Vol. 16 No. 1-2, pp. 17-26.

Fishbein, M. and Ajzen, I. (2010), Predicting and Changing Behavior: The Reasoned Action Approach, Psychology Press, New York, USA. 
Giacomin, J. (2014), "What Is Human Centred Design?”, The Design Journal, Taylor \& Francis, Vol. 17 No. 4 , pp. 606-623.

Greening, L.A., Greene, D.L. and Difiglio, C. (2000), "Energy efficiency and consumption - the rebound effect a survey", Energy Policy, Elsevier, Vol. 28 No. 6-7, pp. 389-401.

Hassenzahl, M. (2013), "User experience and experience design", The Encyclopedia of Human-Computer Interaction, The Interaction Design Foundation, Vol. 2.

Hubka, V. and Eder, W.E. (2012), Theory of Technical Systems: A Total Concept Theory for Engineering Design, Springer Science \& Business Media.

Krippendorff, K. (1989), "On the essential contexts of artifacts or on the proposition that design is making sense (of things)", Design Issues, JSTOR, Vol. 5 No. 2, pp. 9-39.

Krippendorff, K. (2004), "Intrinsic motivation and human-centred design", Theoretical Issues in Ergonomics Science, Taylor \& Francis, Vol. 5 No. 1, pp. 43-72.

Krippendorff, K. (2005), The Semantic Turn: A New Foundation for Design, CRC Press.

Kumar, V. (2012), 101 Design Methods: A Structured Approach for Driving Innovation in Your Organization, John Wiley \& Sons, New Jersey, USA.

Lilley, D. et al. (2017), "Design interventions for sustainable behaviour", Design for Behaviour Change, Routledge, pp. 40-57.

Michie, S. et al. (2015), "Behaviour change techniques: the development and evaluation of a taxonomic method for reporting and describing behaviour change interventions (a suite of five studies involving consensus methods, randomised controlled trials and analysis of qualitative da", Health Technology Assessment, NIHR Journals Library, Vol. 19, p. 99.

Mitcham, C. and Schatzberg, E. (2009), "Defining technology and the engineering sciences", Philosophy of Technology and Engineering Sciences, Elsevier, pp. 27-63.

Niedderer, K., Clune, S. and Ludden, G. (2018), Design for Behaviour Change: Theories and Practices of Designing for Change, Routledge, New York, USA.

Norman, D.A. (2004), Emotional Design: Why We Love (or Hate) Everyday Things, Basic Civitas Books.

Norman, D.A. (2013), The Design of Everyday Things: Revised and Expanded Edition, Basic books.

Otto, K. and Wood, K. (2001), Product Design: Techniques in Reverse Engineering and New Product Development, Prentice Hall, New Jersey, USA. available at: http://books.google.co.in/books?id=up8nA QAAMAAJ

Poel, I.R. and Royakkers, L.M.M. (2011), Ethics, Technology and Engineering: An Introduction, WileyBlackwell, West Sussex, England.

Roozenburg, N.F.M. and Eekels, J. (1995), Product Design: Fundamentals and Methods, John Wiley \& Sons Ltd, West Sussex, England.

Sanders, E.B.N. and Stappers, P.J. (2008), "Co-creation and the new landscapes of design”, CoDesign.

Taylor, N., Conner, M. and Lawton, R. (2012), "The impact of theory on the effectiveness of worksite physical activity interventions: a meta-analysis and meta-regression”, Health Psychology Review, Taylor \& Francis, Vol. 6 No. 1, pp. 33-73.

Thaler, R.H. (2015), Misbehaving: The Making of Behavioral Economics, WW Norton \& Company.

Tromp, N., Hekkert, P. and Verbeek, P.-P. (2011), "Design for socially responsible behavior: a classification of influence based on intended user experience", Design Issues, MIT Press, Vol. 27 No. 3, pp. 3-19.

Tversky, A. and Kahneman, D. (1974), "Judgment under uncertainty: Heuristics and biases", Science, American association for the advancement of science, Vol. 185 No. 4157, pp. 1124-1131.

Ulrich, K. and Eppinger, S. (2000), Product Design and Development, Irwin McGraw-Hill, New York, USA.

Wickens, C. (1992), Engineering Psychology and Human Performance, second, Harper Collins Publishers, New York, USA.

Yin, R.K. (2014), Case Study Research and Applications: Design and Methods, 5th ed., Sage publications.

Young, W. et al. (2010), "Sustainable consumption: green consumer behaviour when purchasing products", Sustainable Development, Wiley Online Library, Vol. 18 No. 1, pp. 20-31. 